\title{
Allergic disease in infants up to 2 yr of age in relation to plasma omega-3 fatty acids and maternal fish oil supplementation inpregnancy and lactation
}

\author{
Catrin Furuhjelm, Kristina Warstedt, Malin Fagerås Böttcher, Karin Fälth-Magnusson, \\ Johanna Larsson, Mats Fredriksson and Karel Duchén
}

\section{Linköping University Post Print}

N.B.: When citing this work, cite the original article.

Original Publication:

Catrin Furuhjelm, Kristina Warstedt, Malin Fagerås Böttcher, Karin Fälth-Magnusson, Johanna Larsson, Mats Fredriksson and Karel Duchén, Allergic disease in infants up to $2 \mathrm{yr}$ of age in relation to plasma omega-3 fatty acids and maternal fish oil supplementation inpregnancy and lactation, 2011, Pediatric Allergy and Immunology, (22), 5, 505-514.

http://dx.doi.org/10.1111/j.1399-3038.2010.01096.x

Copyright: John Wiley and Sons http://www.wiley.com/

Postprint available at: Linköping University Electronic Press http://urn.kb.se/resolve?urn=urn:nbn:se:liu:diva-61945 


\section{Allergic disease in infants up to two years of age in relation to plasma omega-3 fatty acids and maternal fish oil supplementation \\ in pregnancy and lactation.}

Catrin Furuhjelm $\mathrm{MD}^{1}$, Kristina Warstedt $\mathrm{BSc}^{1,2}$, Malin Fagerås $\mathrm{PhD}^{1,2}$, Karin Fälth-

Magnusson MD, $\mathrm{PhD}^{1}$, Johanna Larsson $\mathrm{MD}^{3}$, Mats Fredriksson $\mathrm{PhD}^{4}$, Karel Duchén MD,

$\mathrm{PhD}^{1}$

${ }^{1}$ Division of Pediatrics, Department of Clinical and Experimental Medicine, Faculty of Health Sciences, Linköping University, Linköping, Sweden.

${ }^{2}$ Clinical and Experimental Research, Faculty of Health Sciences, Linköping University, Linköping, Sweden

${ }^{3}$ Pediatric Clinic, Ryhov Hospital, Jönköping, Sweden.

${ }^{4}$ Division of Occupational and Environmental Medicine, Department of Clinical and Experimental Medicine, Faculty of Health Sciences, Linköping, Sweden

Running title: Fish oil and allergy in infants.

ClinicalTrial.gov identifier: NCT00892684

Corresponding author: Catrin Furuhjelm

Division of Pediatrics

Department of Clinical and Experimental Medicine

Faculty of Health Sciences

SE-581 85 Linköping.

Sweden

Phone: +46-13-221324 Fax: +46-13-148265

E-mail: catrin.furuhjelm@ telia.com 
Allergic disease in infants up to two years of age in relation to plasma omega-3 fatty acids and maternal fish oil supplementation in pregnancy and lactation. Furuhjelm, C, Warstedt, K, Fagerås , M, Fälth-Magnusson, K, Larsson, J, Fredriksson, M, Duchén, K. Pediatr Allergy Immunol.

\section{Abstract}

Background: We have previously reported a protective effect of maternal omega-3 long chain polyunsaturated fatty acids ( $\omega-3$ LCPUFA) supplementation in pregnancy and lactation on $\operatorname{IgE}$ associated eczema and food allergy in the infant during the first year of life.

Objectives: To investigate whether the effects of the LCPUFA supplementation on IgE associated diseases last up to two years of age and assess the relationship between plasma proportions of $\omega-3$ PUFAs and the frequency and severity of infant allergic disease.

Patients and Methods: 145 pregnant women, at risk of having an allergic infant, were randomised to daily supplementation with $1.6 \mathrm{~g}$ eicosapentaenoic acid (EPA) and $1.1 \mathrm{~g}$ docosahexaenoic acid (DHA) or placebo starting in the $25^{\text {th }}$ gestational week and continuing through 3.5 months of breastfeeding. Clinical examinations, skin prick tests, and analysis of maternal and infant plasma phospholipid fatty acids and infant specific IgE were performed. Results: No difference in prevalence of allergic symptoms was found between the intervention groups. The cumulative incidence of $\operatorname{IgE}$ associated disease was lower in the $\omega-3$ supplemented group $(6 / 54,13 \%)$ compared to the placebo group $(19 / 62,30 \%, \mathrm{p}=0.01)$. Higher maternal and infant proportions of DHA and EPA were associated with lower prevalence of $\operatorname{IgE}$ associated disease $(\mathrm{p}=0.01-0.05)$ in a dose dependent manner. Higher maternal and infant proportions of DHA and EPA were found if the infants presented none, as compared to multiple allergic symptoms, $(\mathrm{p}<0.05)$ regardless of sensitisation.

Conclusions: The $\omega-3$ supplementation offered no obvious preventive effect on the prevalence of clinical symptoms of allergic disease but the decrease in cumulative incidence of $\operatorname{IgE}$ 
associated disease seen during the first year still remained until two years of age.

Furthermore, high plasma proportions of DHA and EPA in maternal and infant serum phospholipids were associated with less IgE associated disease and a reduced severity of the allergic phenotype.

\author{
Key words: $\quad$ Allergy, Eczema, Fatty acids, Pregnancy, \\ Lactation, Dietary supplements, Infant,
}

Send requests for off prints to Catrin Furuhjelm, Dept of Pediatrics, Linköping University Hospital, 58285 Linköping, Sweden

\title{
Introduction
}

The long chain polyunsaturated fatty acids (LCPUFA) docosahexaenoic acid (DHA, C22: 6 $\omega-3)$ and eicosapentaenoic acid (EPA, C20: 5 $\omega-3)$ have been shown to possess immunomodulatory properties and are abundant in oily fish $(1,2)$. Observational studies report that oily fish in the maternal diet during pregnancy (3) as well as in the infant's diet 
during the first year (4) decreases the risk of allergic sensitisation and disease later in life. Furthermore, although still controversial, low levels of DHA and EPA have been demonstrated both in cord blood of infants who later develop allergies, and in children with allergic disease (5). Immune responses against antigens have been detected in the fetus as early as at the 25th gestational week (gw) (6), and possible protective effects from dietary supplementation with EPA and DHA during pregnancy have been reported on sensitisation and severity of eczema in infants (7) as well as on asthma in adolescents (8). We previously reported a protective effect of maternal DHA and EPA supplementation in pregnancy and lactation on skin sensitisation, $\operatorname{IgE}$ mediated food reactions and $\operatorname{IgE}$ associated eczema during the first year of life (9). Thus, the primary aim of this report is to corroborate these findings at 24 months of age in the infants and to assess whether there is a relationship between the

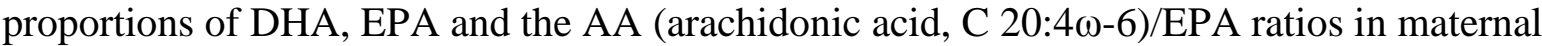
and infant plasma phospholipids and the frequency of $\operatorname{IgE}$ associated disease. The first year we found no effect on the prevalence of clinical symptoms per se (9) and the immediate clinical significance of the low rate of early $\operatorname{IgE}$ associated disease was not elucidated even though it might be beneficial for lowering the asthma prevalence later in life (10). In this report the severity of eczema and number of allergic symptoms up to two years of age in the infants are related to maternal $\omega-3$ supplementation and maternal and infant DHA, EPA and AA/EPA ratios in plasma phospholipids.

\section{Material and Methods}

\section{Inclusion and dietary intervention}

In summary, 145 pregnant women were recruited through antenatal care clinics during a twoyear period in 2003-2005. At least one family member had current or previous allergic 
symptoms i.e. bronchial asthma, eczema, allergic food reactions, itching and running eyes and nose at exposure to pollen, pets or other known allergens. The clinical symptoms were assessed in a structured interview performed by one of the three research nurses (9).

Exclusion criteria were allergy to soy or fish, treatment with anti-coagulants or $\omega-3$ fatty acid supplements. The mothers were randomised to dietary supplementation with nine capsules a day containing $\omega$-3 fatty acids (35\% EPA, 1.6 g/day and 25\% DHA, $1.1 \mathrm{~g} /$ day, $\mathrm{n}=70$ ) or soybean oil (58\% linoleic acid, LA, $2.5 \mathrm{~g} /$ day and 6\% $\alpha$-linolenic acid, LNA, $0.28 \mathrm{~g} / \mathrm{day}$, $\mathrm{n}=75$ ) as a placebo through numbered containers prepared by the producer (Pharma Nord, Vejle, Denmark). The mothers, as well as the staff handling clinical and laboratory follow up, were blinded to group allocation and the mothers were identified by their study number only. In both preparations the antioxidant $\alpha$-tocopherol was used in similar amounts ( $\omega$-3 group: 28 $\mathrm{mg} /$ day placebo: $36 \mathrm{mg} /$ day) to assure the stability of the oil. The supplementation started at the 25 th week of gestation and the mean time of supplementation was 30.7 weeks (SD: +/-5.8 w range: $15.1-42.1, \omega-3: 29.8$ weeks, placebo: 31.3 weeks, ns). Sixteen (23\%) of the mothers in the $\omega$-3 LCPUFA and nine (12\%) in the placebo group did not complete the minimum 15 weeks of supplementation required, i.e. throughout pregnancy. On average, these mothers took the supplementation for 5.3 weeks (SD 3.4) in the $\omega-3$ supplemented group and 5.3 weeks (SD 4.2) in the placebo group. Reasons for discontinuing the intervention were inability to swallow capsules $(n=9)$, nausea $(n=6)$, abdominal pain $(n=3)$, forgot to take capsules $(n=3)$ and miscellaneous $(n=4)$. The content of the capsules did not have an impact on reasons for withdrawal.

\section{Follow up and data collection}

The families were followed up according to Figure I. Research nurses assessed the infants at 3, 6 and 12 months of age. A paediatrician (JL or CF) examined the infants at any time if 
clinical symptoms of allergic disease were suspected and all infants were examined at 24 months of age. The severity of eczema was assessed by rating according to SCORAD (11). Blood samples were taken from the mothers one week after delivery and from the infants at delivery (cord blood) and at 3,12 and 24 months of age. The samples were immediately frozen and stored at $-70^{\circ} \mathrm{C}$. The families completed validated allergy questionnaires (12) regarding environmental factors, the infant's diet and development of clinical symptoms in the infant at 3, 6, 12 and 24 months of age. The $\omega-3$ group and the placebo group were similar regarding possible confounders; maternal allergic symptoms, maternal positive Phadiatop®, eczema or food reactions in the immediate family, breastfeeding at 3 and 6 months, number of siblings (9), day care attendance, one or two parents with allergic disease and exposure to tobacco smoke or furry pets up to two years of age (data not shown) but caesarean sections were more common in the placebo group $(14 / 66,21 \%$ compared to the $\omega$ - group $(4 / 54,7 \%$, $\mathrm{p}<0.05)$. Ninety-seven percent of the mothers in the intervention groups breast fed, at least partly, at three months and $87 \%$ at 6 months. No formula containing long chain $\omega-3$ fatty acids was used. After 4 weeks of supplementation some mothers reported belching; 11/80 (14\%) and 10/11 were supplemented with $\omega-3$ fatty acids $(\mathrm{p}=0.001)$. At the follow-up investigations, the staff was instructed not to ask any specific questions that could reveal maternal opinion regarding group allocation. The mothers who were unable to complete the intervention $(n=25)$ were invited to a clinical examination of their infants comprising skin prick tests (SPTs) but no blood sampling at 6 and 24 months (Fig.1). Thus, a follow up at 2 years was accomplished for 143/145 families.

A certified dietician assessed the maternal dietary intake of energy, total fat and $\omega-6$ and $\omega-3$ polyunsaturated fatty acids from maternal food diaries filled out three days in a row at $25^{\text {th }}$ gestational week and 6 months after delivery. The results were the same in the $\omega-3$ and placebo groups (9). These finding were reflected in similar proportions of DHA and EPA in 
maternal plasma phospholipids in both groups before supplementation (9). None of the mothers or infants took any additional fatty acid supplements.

\section{Clinical definitions}

Food reaction: gastrointestinal symptoms, hives, aggravated eczema or wheezing following ingestion of a certain food with recovery after food elimination and reoccurrence of symptoms after reingestion of the particular food. If food specific positive SPT or serum IgE antibodies were present, the food reaction was considered as IgE mediated. Eczema: reoccurring and itching eczematous, lichenified or nummular dermatitis, according to the definition by Seymour in 1987 (13). If detectable IgE antibodies or a positive SPT were present, it was defined as IgE associated eczema. Asthma: doctor diagnosed wheezing at least three times during the first two years (14). IgE associated asthma was defined as asthma with the presence of IgE antibodies or positive SPT. Rhinoconjunctivitis: seasonal itching and running eyes and nose. It was considered as $\operatorname{IgE}$ mediated if there was corresponding positive SPT or detectable specific IgE antibodies. Symptoms of eczema, food reaction, asthma or rhinoconjunctivitis were considered as clinical symptoms of allergic disease. Concomitant sensitisation defined IgE associated allergic disease.

\section{Sensitization}

Maternal serum IgE antibodies to a panel of inhalant antigens (Phadiatop®) were analysed by the UniCap ${ }^{\circledR}$ Pharmacia CAP System ${ }^{\mathrm{TM}}$ (Phadia, Uppsala, Sweden).

SPTs were performed in the infants at 6 and 12 months of age with milk, egg, wheat and cat. At 24 months of age, timothy and birch were added to the test panel. Food allergens were tested prick to prick and the inhalant allergens were extracts purchased from ALK-ABELLÓ, Hørsholm, Denmark, Soluprick®. A wheal diameter $\geq 3 \mathrm{~mm}$ was considered positive. 
Specific IgE antibodies towards egg, milk, wheat and cat were analyzed in serum samples from the infants at 12 and 24 months of age. At 24 months timothy-grass and birch were added to the analysis. The detection limit was $0.35 \mathrm{kU} / \mathrm{l}$.

\section{Fatty acid analysis}

Analysis of phospholipids was performed separating lipid fractions on a SEP-PAK aminopropyl cartridge (Waters Sverige AB, Sollentuna, Sweden) according to a method originally described by Kaluzny et al.(15). Samples were trans-methylated in methanolic$\mathrm{HCl}-3 \mathrm{~N}(\mathrm{VWR})$ at $80^{\circ} \mathrm{C}$ for $4 \mathrm{~h}$. The fatty acid methyl esters were separated by Agilent Technologies 6890N Network GC System gas chromatograph (Agilent Technologies, Stockholm, Sweden). C21:0 methyl ester (Larodan, Malmö, Sweden) was added as an internal standard and the fatty acid methyl esters were identified by comparing the retention times of the peaks with those of a known standard (Mixture Me 100, Larodan Fine Chemicals AB, Malmö, Sweden). The levels were expressed as mol\% (16).

\section{Statistics}

Power calculations for planning adequate sample size were performed based on a previous study (17). In order to detect a $40 \%$ difference in the prevalence of clinical symptoms of allergic disease, with $80 \%$ power and a probability of 0.05 at least 134 women had to be included in this study. The categorical data of the two groups were analyzed by chi- 2 tests and when the expected count was less than 5, the Fisher's exact test was used. The means of the continual variables by Student's t-test. If not normally distributed, the Mann-Whitney test was applied. Multiple 
logistic regression was used to calculate the odds ratios for developing allergic sensitisation and disease in the $\omega-3$ supplemented group compared to the placebo group and to find confounders in the comparison between subgroups (Fig 2, Table 4). Maternal AA levels at inclusion were not equal in the two groups in spite of randomization and were therefore considered as possible confounders in addition to the factors described in the Follow up and data collection. All confounders were run in the model and effect modifiers (altering the odds ratio $>10 \%$ ), identified for each outcome, were considered in calculating adjusted odds ratios (aOR). Mother-infant pairs were divided into groups according to quartile of phospholipid $\omega$ 3 proportions (Fig 2) and were related to the frequency of infant $\operatorname{IgE}$ associated disease. Chi-2 and Chi-2 trend (Extended Mantel-Haenszel chi-square test for linear trend) were used to assess the differences in prevalence of IgE associated disease between the quartile groups. A difference was considered statistically significant at a two-tailed p-value of $<0.05$. Statistic analyses were performed using SPSS software 15.0 for Windows (SPSS Inc, Chicago, Illinois, USA).

\section{Ethical considerations}

The Human Research Ethics Committee of the Medical Faculty at Linköping University approved the study. All parents gave written informed consent.

\section{Results}

\section{Sensitization and allergic symptoms}

The cumulative incidence (0-24 m) of positive SPTs, particularly to food, in the $\omega-3$ group was lower compared to the placebo group but symptoms of allergic disease in the infants were equally frequent in the two groups (Table 1). IgE mediated food reactions, IgE associated 
eczema and any IgE associated disease were, however, significantly less frequent in the $\omega-3$ group compared to the placebo group during the infant's first two years of life (Table 1). Crude and adjusted odds ratios are presented in Table 2. When analysing the subgroup of children whose mothers did not have allergic symptoms separately there was still a trend towards lower incidence of $\operatorname{IgE}$ associated disease in the $\omega-3$ group $(\omega-3: 1 / 14,7 \%$ vs. placebo: $9 / 23,39 \%, \mathrm{p}=0.056$ ) while it was not as evident in the group of children with maternal history of allergy $(\omega-3: 5 / 40,13 \%$ vs. placebo: $10 / 39,26 \%, p=0.14)$. There were no significant differences between the $\omega$ - 3 group and the placebo group regarding the point prevalence of sensitisation or allergic symptoms or IgE associated disease at 24 months of age (Table 1).

Among the 25 mothers who did not complete the intervention (Fig.1) 15/24 (62\%) reported allergic symptoms in the infant and 7/18 infants (38\%) were diagnosed with IgE associated disease up to 24 months. These results did not differ from the placebo group but were significantly higher than in the $\omega-3$ group ( $p=0.03$ and 0.01 respectively).

In an intention to treat analysis there was a trend towards a lower cumulative incidence of positive SPT's to food and IgE associated disease in the $\omega-3$ supplemented group compared to the placebo group ( $\mathrm{p}=0.06-0.07$, data not shown).

\section{Plasma proportions of LCPUFA.}

Mothers and infants in the $\omega-3$ supplemented group had higher plasma proportions of $\omega-3$ LCPUFA compared to the placebo group during the first year but this difference was not apparent in the infants at two years of age (Table 3 ).

We divided the mother- infant pairs into quartiles according to maternal phospholipid proportions of DHA and the AA/EPA ratios (Fig 2), in parallel with the report by Mihrshahi et al (18). For each quartile the frequency of $\operatorname{IgE}$ associated disease, allergic symptoms 
without sensitisation, and absence of allergic symptoms with or without sensitisation in the infants are given in Fig 2. The cumulative incidence of $\operatorname{IgE}$ associated disease was lower in the groups of children whose mothers were in the higher quartiles of phospholipid DHA (Fig 2A) and also among the infants with DHA proportions in the higher quartiles at 12 months of age (Chi-2: $\mathrm{p}=0.05, \mathrm{p}$ for trend $=0.003$, data not shown). No such relations were found for exposure quartiles of infant DHA proportions in cord blood phospholipids at 3 or 24 months of age. The opposite results were found regarding the AA/EPA ratio, i.e. mothers with AA/EPA ratios in the lower quartiles less often gave birth to children with $\operatorname{IgE}$ associated disease (Fig.2B). There was also significant trends towards lower incidence of IgE associated disease in the lower quartiles of AA/EPA ratios in infant phospholipids at birth and at 3 months of age (Chi-2: $\mathrm{p}=\mathrm{ns}$ for both, but $\mathrm{p}$ for trend $=0.01$ and 0.03 respectively, data not shown) but not in infant phospholipids at 12 nor at 24 months (data not shown). In a multiple regression model no confounders were found that significantly changed these results. We found no associations between LA or LNA proportions in mother or infant at any time point and allergic disease, sensitisation or IgE associated disease (data not shown).

\section{Severity of allergic disease.}

Regardless of sensitisation, $32 \%$ (6/19) of the infants with clinical allergic symptoms in the $\omega$ 3 group and $50 \%(14 / 28)$ in the placebo group had more than one allergic symptom, i.e. eczema, food allergy, asthma and/or rhinoconjunctivitis during the first two years of life (ns). However, the proportions of DHA and EPA were higher and the AA/EPA ratios were lower in maternal and infant phospholipids if the infant was non-symptomatic, compared to the infants who developed two or more allergic symptoms $(\mathrm{p}<0.05$ at several time points, Table 4). Furthermore, in all infants, more than one allergic symptom during the first two years of life was more frequent in infants with IgE associated disease than in the group of 
symptomatic infants without sensitisation $(16 / 24,67 \%$ compared to $3 / 20,15 \%, \mathrm{p}=0.001)$. Mean SCORAD among the infants with eczema in the placebo group was $13.3(\mathrm{SD} 7.2, \mathrm{n}=$ 20 ) and in the $\omega-3$ group 17.8 (SD 9.6, $\mathrm{n}=11, \mathrm{~ns})$. The infants were evaluated in average 2.6 times in both groups during the follow up with the highest score included in the analysis but merely two infants had SCORAD > 25. There was no association between SCORAD rates and fatty acid status (data not shown).

\section{Discussion}

In this study, we report that maternal supplementation with $\omega$-3 PUFA during pregnancy and lactation is related to lower cumulative incidence of allergic sensitisation and $\operatorname{IgE}$ related disease up to 24 months of age. We further report a significant relationship between higher $\omega$ 3 PUFA proportions in maternal and infant phospholipids and lower frequency and less severity of allergic disease during the first two years of life.

Our findings corroborate in some aspects previous reports. Two earlier trials have evaluated $\omega-3$ supplementation during pregnancy in relation to sensitisation (7) and asthma (8) in the infants. In the study by Dunstan et al (7) it was shown that daily dietary supplementation with $1.1 \mathrm{~g}$ EPA and $2.2 \mathrm{~g}$ DHA to atopic mothers during late pregnancy $(\mathrm{n}=89)$ lowered the risk of sensitisation to egg and severe eczema $(\mathrm{SCORAD}>25)$ at 12 months in the $\omega-3$ as compared to the placebo supplemented group the first year of life, but the infants were not examined at 24 months or later for allergic outcomes (7). A population-based study by Olsen et al found a lower prevalence of allergic asthma in teenagers whose mothers had received $2.7 \mathrm{~g} \omega$-3

LCPUFA during the second half of pregnancy $(n=263)$ as compared to adolescents whose mothers had received olive oil $(n=136)$. However, this difference did not appear when comparing the fish oil group to a group whose mothers received no supplement (8). In our study, the prevalence of allergic symptoms and IgE associated disease in the group whose 
mothers did not complete the intervention was similar to the placebo group and significantly higher than in the $\omega-3$ supplemented group, strengthening our results.

In the CAPS study mothers $(\mathrm{n}=376)$ were supplied with low $\omega-6$ PUFA containing oils and margarines from 36 weeks of gestation. After weaning the infants received $500 \mathrm{mg}$ tuna fish oil daily (37\% $\omega$-3 PUFA; $185 \mathrm{mg}$ daily). At 18 months of age there was a decreased prevalence of wheeze in the fish oil group and higher plasma $\omega^{-3}$ PUFA levels were associated with lower bronchodilator use, irrespective of the supplementation group (18). The infants were given a rather low dose of $\omega-3$ and DHA and EPA were not analysed separately in relation to IgE associated manifestations, which could explain the lack of dose response relationship. Follow-up at 3 years indicated that the fish oil group had reduced cough, but not wheeze (19). However, no effect of fish oil supplementation was seen on the other endpoints measured such as eczema, serum IgE concentration, or doctor's diagnosis of asthma.

Our sample size was calculated based on the cumulative incidence of allergic disease during the first 18 months of life (17). However, for instance the cumulative incidence of eczema in this study was $20 \%$ in the $\omega-3$ and $31 \%$ in the placebo group, and thus less common than expected. In order to dismiss such a difference between the two groups as a type II error, with an $80 \%$ power at a 0.05 significance level, 246 mothers would have been needed in each group. Nevertheless, we found significantly lower frequencies of $\operatorname{IgE}$ associated disease in the infants during this period. Thus, the relationship between $\omega-3$ supplementation and clinical symptoms combined with allergic sensitisation seem to be of more biological importance than clinical symptoms alone. The objective of this study was not to evaluate the tolerability or the dose of fish oil; it was mainly to prove any effect at all from fish oil supplementation. However, when performing an intention to treat analysis the preventive effect of the supplementation was not obvious, suggesting that increased compliance would be preferable, maybe by decreasing the daily dose to make it more tolerable. 
The low prevalence of allergic symptoms and sensitisation in the infants at 24 months of age in this study reflects the general decrease of these symptoms commonly seen after the first year $(20,21)$. To rule out any effect from the $\omega-3$ supplementation on the point prevalence of allergic symptoms or sensitisation at 24 months, 300 infants/group are needed, which is a study beyond our ability.

When pooling patients regardless of the supplementation, we found an inverse dose response association between high $\omega-3$ fatty acids in mother and infants and appearance of $\operatorname{IgE}$ associated disease during the first two years of life. This thus suggests that the higher the levels of $\omega$-3 LCPUFA in serum, the lower the risk of developing IgE associated disease in the infants during the first 2 years of life. However, this does not tell us the maternal dose required in order to protect her infant from $\operatorname{IgE}$ associated disease. We also observed an association between high DHA and EPA proportions and low AA/EPA ratios in maternal and infant plasma phospholipids and a less severe disease, expressed as number of symptoms. Presumably, this might be associated to the decrease in allergic sensitisation among the infants presenting clinical symptoms. The relationship between disease severity and allergic sensitisation found in this study strengthens this explanation. Hence, $\omega$-3 PUFA supplementation, although not preventing the development of clinical disease, may represent a significant clinical benefit for the families by preventing allergic sensitisation. Animal studies, reporting that dietary DHA and EPA may resolve inflammation and hamper the severity of the allergic disease, corroborate these findings (22).

Our SCORAD data was not associated to the supplementation or phospolipid fatty acids but the significance of the SCORAD may be questioned. The ratings were generally very low due to close follow up and intense treatment of infants from families with previous experience of eczema. 
As expected in this age group, asthma, and particularly IgE associated asthma, was rare in our study. However, early development of eczema and skin sensitisation to food, particularly egg, in the first two years of life, is related to an increased risk of later development of asthma bronchiale (10) which highly motivates further follow up regarding asthma and sensitisation against inhalant allergens among the infants in this study.

DHA and EPA may act through several anti-inflammatory mechanisms. They inhibit expression of inflammatory genes (COX-2, IL-1 $\alpha, 5$-LOX etc) and adhesion molecules, influence the antigen presenting cells (23), reduce lymphocyte proliferation (24) and alter cytokine production (25). Low AA/EPA ratios in maternal plasma were associated with low incidence of IgE associated disease in the infants in this study. EPA and AA compete for the same enzymes, COX (cyklooxygenase) and LOX (lipooxygenase) (1). Low maternal AA/EPA ratios may be associated with decreased maternal secretion of AA derived $\mathrm{PGE}_{2}$, possibly in favour of less potent eicosanoids $\left(\mathrm{PGE}_{3}, \mathrm{LTB}_{5}\right)$ derived from EPA and DHA (16). $\mathrm{PGE}_{2}$ regulates antigen presenting cell function, inhibits IL2 and IFN $\gamma$ production, enhances the formation of IL4 and IL5 and induces B-cells to switch to IgE production (23). Moreover, DHA and EPA are important in the synthesis of resolvins and protectins, novel substances which regulate cellular traffic into inflammatory sites (2). Thus, there are several explanatory models by which $\omega-3$ PUFA may balance the normally Th2 skewed immune responses in infancy in order to prevent prolonged IgE sensitisation.

In this study maternal blinding might be incomplete due to fish tasting belching reported by some mothers in the $\omega-3$ supplemented group and diagnosis of clinical symptoms is dependent on the mother's description and expectations. However, positive SPTs and detection of specific IgE antibodies in blood samples are objective measures. Further, all staff members working with the intervention and follow up were blinded throughout the whole study. 
The rationale for soybean oil as a reliable placebo in this study may be questioned. Despite the LA content in the placebo capsule $(2.5 \mathrm{~g} / \mathrm{d}$, in relation to daily dietary intake of $8.0 \mathrm{~g} / \mathrm{d}$ LA in the placebo and 7,7 $\mathrm{g} / \mathrm{d}$ in the $\omega-3$ supplemented mothers) the maternal and infant LA and AA plasma proportions in the placebo group corresponded to previous observations in normal pregnancy (26) and early infancy (27). The proportions of LA and AA in the $\omega-3$ group decreased compared to the placebo group due to the increase of $\omega-3$ proportions as previously shown (28). Furthermore, LA levels were not associated to allergic disease or sensitisation in the infant at any point. However, the content of vitamin $\mathrm{E}$ in the oils differed somewhat between the two groups. Vitamin $\mathrm{E}$ is an antioxidant with a recommended daily intake during pregnancy of $15-20 \mathrm{mg}$. It has been reported to possibly decrease the risk of developing asthma, eczema (29) and sensitization (30) in childhood. However, the reduced risk of sensitisation has been seen at intakes of vitamin E below up to but not above $7 \mathrm{mg} /$ day (30) and all mothers in this study received more than $25 \mathrm{mg} /$ day.

In conclusion $\omega$-3 PUFA supplementation decreases the cumulative incidence of $\operatorname{IgE}$ associated disease up to 2 years of life and this effect was related to maternal and infant $\omega-3$ LCPUFA plasma proportions in a dose dependent manner. The $\omega-3$ LCPUFA might mitigate the severity of the allergic phenotype, possibly through preventing allergic sensitisation, as high maternal and infant plasma $\omega-3$ proportions were associated with fewer allergic symptoms in the infants.

This suggests that fish oil in the diet during pregnancy and early in life may be important if there is a high risk for allergies in the family. The value of decreasing allergic sensitisation in early life by $\omega$-3 PUFA supplementation for the development of asthma bronchiale later in life needs to be further assessed. 
Acknowledgements

We wish to thank all the families participating in this study and our excellent research nurses

Lena Lindell, Kicki Helander and Linnea Andersson. We also appreciate the dedicated work of our dietician Katarina Dahlgren. Professor Birgitta Strandvik and Mrs. Berit Holmberg, Department of Pediatrics, Institute of the Health of Women and Children, Gothenburg University kindly shared their expertise regarding the PUFA phospholipids analysis technique. We thank professor Karl-Erik Magnusson for valuable comments on the manuscript. A special thanks to Benjamin Kersley for language advice. For funding we are grateful to: Pharma Nord, Sadelmagervej 30-32 DK-7100 Vejle Denmark, Medical Research Council of Southeast Sweden (FORSS),

The Östergötland County Council, The Ekhaga Foundation, Swedish Asthma and Allergy Association, The Swedish Research Council for Environment, Agricultural Sciences and Spatial Planning (FORMAS), The Swedish Society of Medicine, The Swedish Medical Research Council and Glaxo Smith Kline, Sweden

References

1. Calder PC, Miles EA. Fatty acids and atopic disease. Pediatr Allergy Immunol 2000;11 Suppl 13:29-36.

2. Serhan $\mathrm{CN}$. Novel eicosanoid and docosanoid mediators: resolvins, docosatrienes, and neuroprotectins. Curr Opin Clin Nutr Metab Care 2005;8(2):115-21.

3. Calvani M, Alessandri C, Sopo SM, Panetta V, Pingitore G, Tripodi S, et al. Consumption of fish, butter and margarine during pregnancy and development of allergic sensitizations in the offspring: role of maternal atopy. Pediatr Allergy Immunol 2006;17(2):94-102.

4. Kull I, Bergstrom A, Lilja G, Pershagen G, Wickman M. Fish consumption during the first year of life and development of allergic diseases during childhood. Allergy 2006;61(8):1009-15.

5. Sala-Vila A, Miles EA, Calder PC. Fatty acid composition abnormalities in atopic disease: evidence explored and role in the disease process examined. Clin Exp Allergy 2008;38(9):1432-50.

6. Warner JA, Jones CA, Jones AC, Warner JO. Prenatal origins of allergic disease. J Allergy Clin Immunol 2000;105(2 Pt 2):S493-8. 
7. Dunstan JA, Mori TA, Barden A, Beilin LJ, Taylor AL, Holt PG, et al. Fish oil supplementation in pregnancy modifies neonatal allergen-specific immune responses and clinical outcomes in infants at high risk of atopy: a randomized, controlled trial. $\mathbf{J}$ Allergy Clin Immunol 2003;112(6):1178-84.

8. Olsen SF, Osterdal ML, Salvig JD, Mortensen LM, Rytter D, Secher NJ, et al. Fish oil intake compared with olive oil intake in late pregnancy and asthma in the offspring: 16 y of registry-based follow-up from a randomized controlled trial. Am J Clin Nutr 2008;88(1):167-75.

9. Furuhjelm C, Warstedt K, Larsson J, Fredriksson M, Böttcher MF, Fälth-Magnusson $\mathrm{K}$, et al. Fish oil supplementation in pregnancy and lactation may decrease the risk of infant allergy. Acta Paediatr 2009;98(9):1461-7.

10. Lowe AJ, Hosking CS, Bennett CM, Carlin JB, Abramson MJ, Hill DJ, et al. Skin prick test can identify eczematous infants at risk of asthma and allergic rhinitis. Clin Exp Allergy 2007;37(11):1624-31.

11. Severity scoring of atopic dermatitis: the SCORAD index. Consensus Report of the European Task Force on Atopic Dermatitis. Dermatology 1993;186(1):23-31.

12. Duchén K, Casas R, Fagerås-Böttcher M, Yu G, Björkstén B. Human milk polyunsaturated long-chain fatty acids and secretory immunoglobulin A antibodies and early childhood allergy. Pediatr Allergy Immunol 2000;11(1):29-39.

13. Seymour JL, Keswick BH, Hanifin JM, Jordan WP, Milligan MC. Clinical effects of diaper types on the skin of normal infants and infants with atopic dermatitis. J Am Acad Dermatol 1987;17(6):988-97.

14. Buffum WP, Settipane GA. Prognosis of asthma in childhood. Am J Dis Child 1966;112(3):214-7.

15. Kaluzny MA, Duncan LA, Merritt MV, Epps DE. Rapid separation of lipid classes in high yield and purity using bonded phase columns. J Lipid Res 1985;26(1):135-40.

16. Warstedt K, Furuhjelm C, Duchén K, Fälth-Magnusson K, Fagerås M. The effects of omega-3 fatty acid supplementation in pregnancy on maternal eicosanoid, cytokine, and chemokine secretion. Pediatr Res 2009;66(2):212-7.

17. Oldaeus G, Anjou K, Bjorksten B, Moran JR, Kjellman NI. Extensively and partially hydrolysed infant formulas for allergy prophylaxis. Arch Dis Child 1997;77(1):4-10.

18. Mihrshahi S, Peat JK, Webb K, Oddy W, Marks GB, Mellis CM. Effect of omega-3 fatty acid concentrations in plasma on symptoms of asthma at 18 months of age. Pediatr Allergy Immunol 2004;15(6):517-22.

19. Peat JK, Mihrshahi S, Kemp AS, Marks GB, Tovey ER, Webb K, et al. Three-year outcomes of dietary fatty acid modification and house dust mite reduction in the Childhood Asthma Prevention Study. J Allergy Clin Immunol 2004;114(4):807-13.

20. Wood RA. The natural history of food allergy. Pediatrics 2003;111(6 Pt 3):1631-7.

21. Illi S, von Mutius E, Lau S, Nickel R, Gruber C, Niggemann B, et al. The natural course of atopic dermatitis from birth to age 7 years and the association with asthma. $\mathrm{J}$ Allergy Clin Immunol 2004;113(5):925-31.

22. Ruhl R, Koch C, Marosvolgyi T, Mihaly J, Schweigert FJ, Worm M, et al. Fatty acid composition of serum lipid classes in mice following allergic sensitisation with or without dietary docosahexaenoic acid-enriched fish oil substitution. Br J Nutr 2008;99(6):1239-46.

23. Gottrand F. Long-chain polyunsaturated fatty acids influence the immune system of infants. J Nutr 2008;138(9):1807S-1812S.

24. Prescott SL, Dunstan JA. Prenatal fatty acid status and immune development: the pathways and the evidence. Lipids 2007;42(9):801-10. 
25. Krauss-Etschmann S, Hartl D, Rzehak P, Heinrich J, Shadid R, Del Carmen RamirezTortosa M, et al. Decreased cord blood IL-4, IL-13, and CCR4 and increased TGFbeta levels after fish oil supplementation of pregnant women. J Allergy Clin Immunol 2008;121(2):464-470 e6.

26. Otto SJ, van Houwelingen AC, Badart-Smook A, Hornstra G. Comparison of the peripartum and postpartum phospholipid polyunsaturated fatty acid profiles of lactating and nonlactating women. Am J Clin Nutr 2001;73(6):1074-9.

27. Peng YM, Zhang TY, Wang Q, Zetterstrom R, Strandvik B. Fatty acid composition in breast milk and serum phospholipids of healthy term Chinese infants during first 6 weeks of life. Acta Paediatr 2007;96(11):1640-5.

28. van Houwelingen AC, Sorensen JD, Hornstra G, Simonis MM, Boris J, Olsen SF, et al. Essential fatty acid status in neonates after fish-oil supplementation during late pregnancy. Br J Nutr 1995;74(5):723-31.

29. Martindale S, McNeill G, Devereux G, Campbell D, Russell G, Seaton A. Antioxidant intake in pregnancy in relation to wheeze and eczema in the first two years of life. Am J Respir Crit Care Med 2005;171(2):121-8.

30. Fogarty A, Lewis S, Weiss S, Britton J. Dietary vitamin E, IgE concentrations, and atopy. Lancet 2000;356(9241):1573-4. 
Figures and figure legends

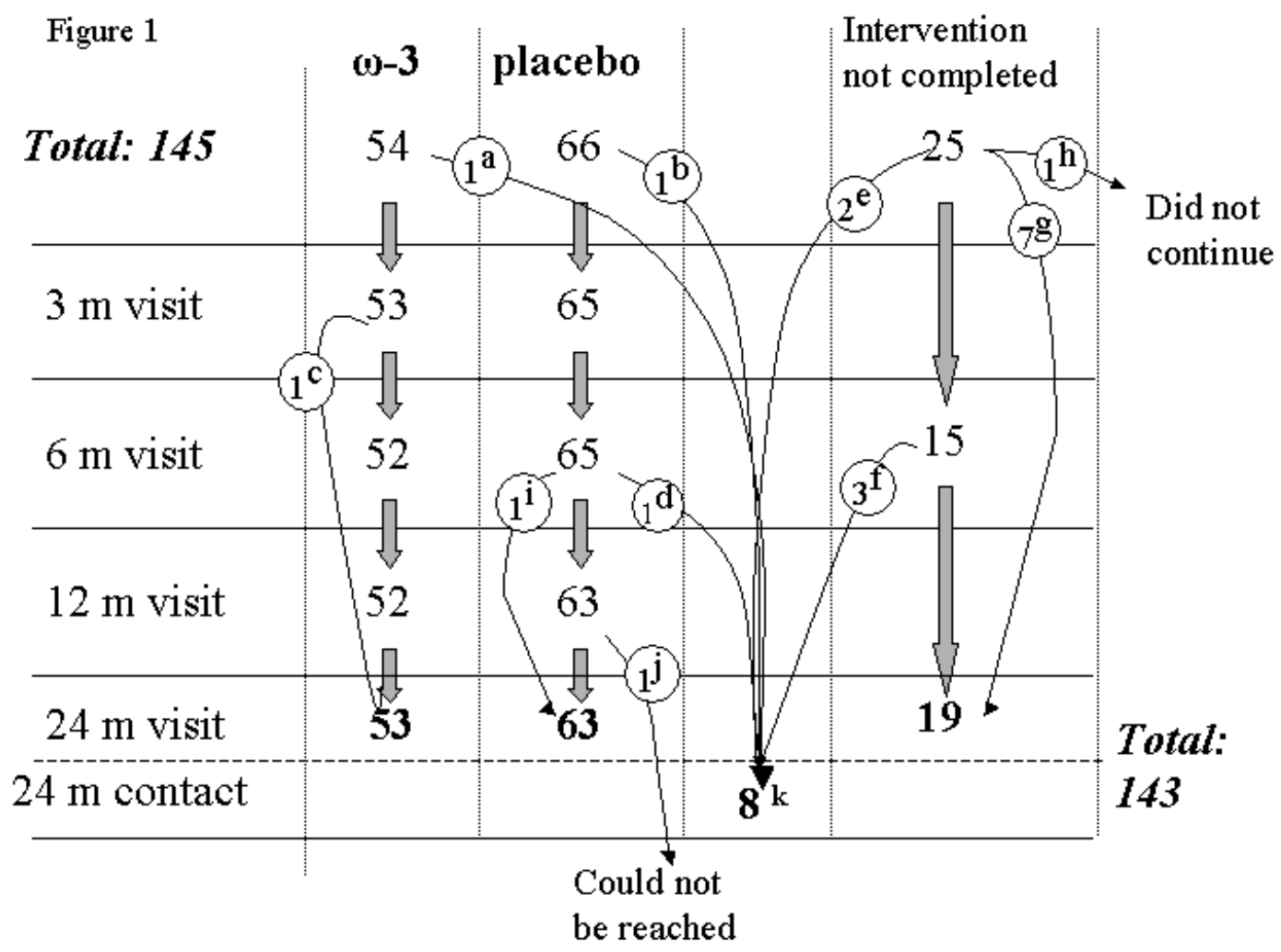

Figure 1. Follow up of the infants. The circles show numbers of infants who have deviated from the ordinary follow-up schedule and the enclosed letter describes how the follow-up was performed.

$\mathbf{a}, \mathbf{b}=$ Moved, were contacted at $24 \mathrm{~m}$. One of them sent in all the questionnaires $(3,6,12$ and 24 months) and none of them described any symptoms of allergy at the 24 months telephone interview.

c, $\mathbf{d}, \mathbf{e}, \mathbf{f}=$ Did not wish to attend all visits but agreed on a 24 months visit or contact. $\mathbf{g}=$ Missed the 6 months visit 
$\mathbf{h}=$ Did not wish to continue.

$\mathbf{i}=$ Moved, missed the 12 months visit.

$\mathbf{j}=$ Moved abroad, could not be reached at 24 months.

$\mathbf{k}=$ The families were interviewed over the telephone by CF or JL and /or filled out the 24

months questionnaire.

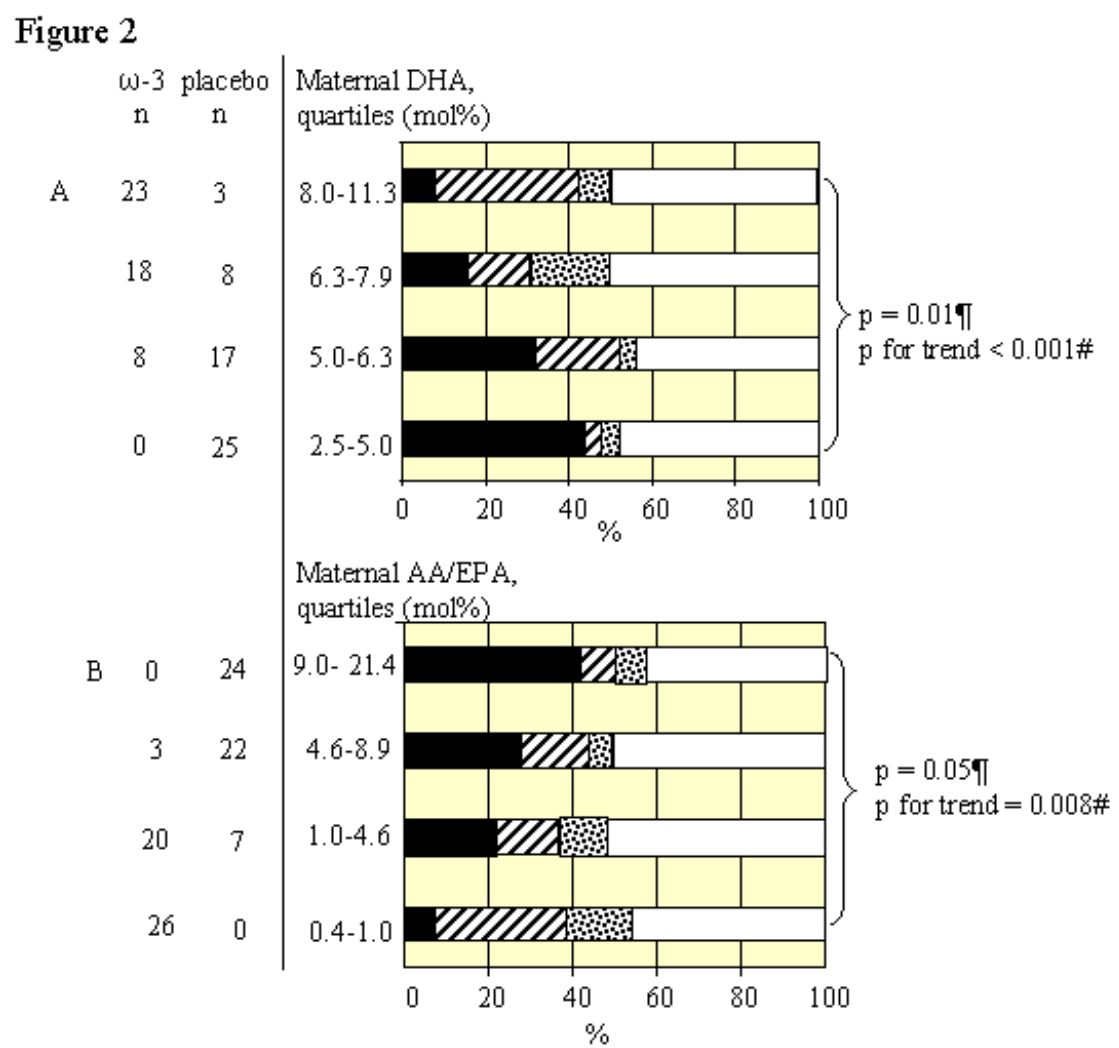

Figure 2. Mother-infant pairs divided into four groups according to quartiles of maternal DHA proportions (A) and AA/EPA ratios (B) one week after delivery. Black bars: Infants with IgE associated disease (allergic symptoms combined with positive SPT and/or circulating specific IgE). Striped bars: Infants with allergic symptoms but no positive SPTs or detectable specific $\operatorname{IgE}$.

Dotted bars: Infants with detectable IgE antibodies or positive SPT without allergic symptoms. White bars: Infants without any allergic symptoms or sensitisation. Thus, the outcome of allergic disease and/or allergic sensitisation in all children in each quartile are 
represented. Infants with $\operatorname{IgE}$ associated disease were less frequent in the families where the mothers had DHA proportions in the higher (A) and AA/EPA ratios in the lower (B) quartiles. II: Chi-2 test $=$ comparison of number of children with IgE associated disease between the quartile groups (black bars).

\#: Chi-2 for linear trend within black bars.

Table 1. Allergic symptoms, sensitisation and $\operatorname{IgE}$ associated disease.

\begin{tabular}{|c|c|c|c|c|c|}
\hline & \multicolumn{5}{|c|}{ Cumulative incidence $0-24 \mathrm{~m}$} \\
\hline & \multicolumn{2}{|c|}{$\omega-3$} & \multicolumn{2}{|c|}{ placebo } & \multirow[b]{2}{*}{$p$-value ${ }^{b}$} \\
\hline & $\mathrm{n}$ & $\%$ & $\mathrm{n}$ & $\%$ & \\
\hline Any food reactions & $6 / 54$ & 11 & $16 / 65$ & 25 & 0.06 \\
\hline Any eczema & $11 / 54$ & 20 & $21 / 65$ & 31 & 0.15 \\
\hline Any asthma & $7 / 54$ & 13 & $8 / 65$ & 12 & 0.91 \\
\hline Any rhinoconjunctivitis & $2 / 54$ & 6 & $2 / 65$ & 2 & 1.0 \\
\hline Positive SPTegg * & $7 / 52$ & 13 & $18 / 61$ & 30 & 0.04 \\
\hline Positive SPT milk * & $4 / 52$ & 8 & $8 / 61$ & 13 & 0.35 \\
\hline Positive SPT wheat* & $1 / 52$ & 2 & $1 / 61$ & 2 & 0.91 \\
\hline Positive SPT food ${ }^{*}+$ & $8 / 52$ & 15 & $21 / 61$ & 34 & 0.02 \\
\hline Any positive $\mathrm{SPT}^{*} \S$ & $10 / 52$ & 19 & $22 / 61$ & 36 & 0.048 \\
\hline IgE egg \| & $7 / 44$ & 16 & $10 / 44$ & 23 & 0.42 \\
\hline IgE milk\| & $8 / 45$ & 18 & $10 / 44$ & 23 & 0.56 \\
\hline IgE wheat $\|$ & $4 / 44$ & 9 & $2 / 44$ & 5 & 0.33 \\
\hline $\operatorname{IgE}$ food $\| t$ & $9 / 45$ & 20 & $14 / 44$ & 32 & 0.20 \\
\hline Any $\operatorname{IgE} \| \S$ & $11 / 44$ & 25 & $15 / 45$ & 33 & 0.39 \\
\hline IgE mediated food reaction $\mathbb{I}$ & $3 / 54$ & 6 & $14 / 65$ & 22 & 0.01 \\
\hline IgE associated eczema** & $5 / 54$ & 9 & $15 / 63 \dagger \dagger$ & 24 & 0.04 \\
\hline IgE associated asthmatt & $2 / 54$ & 4 & 4/64\# & 6 & 0.69 \\
\hline \multirow{6}{*}{$\begin{array}{l}\text { IgE mediated rhino- } \\
\text { conjunctivits } \not \\
\text { Any IgE associated disease }\end{array}$} & & & & & \\
\hline & $1 / 54$ & 2 & $2 / 65$ & 3 & 0.68 \\
\hline & $6 / 54$ & 11 & $19 / 62$ & 31 & 0.01 \\
\hline & \multicolumn{5}{|c|}{ Point prevalence at 24 months } \\
\hline & \multicolumn{2}{|c|}{$\omega-3$} & \multicolumn{2}{|c|}{ placebo } & \\
\hline & $\mathrm{n}$ & $\%$ & $\mathrm{n}$ & $\%$ & p-value ${ }^{b}$ \\
\hline Any food reaction & $2 / 54$ & 4 & $9 / 65$ & 14 & 0.057 \\
\hline Any eczema & $6 / 54$ & 11 & $13 / 65$ & 20 & 0.19 \\
\hline Any asthma & $7 / 54$ & 13 & $8 / 65$ & 12 & 0.91 \\
\hline Any rhinoconjunctivits & $2 / 54$ & 4 & $2 / 65$ & 3 & 1.00 \\
\hline Any allergic disease & $14 / 54$ & 26 & $21 / 63$ & 32 & 0.45 \\
\hline Positive SPT food $\$$ & $6 / 52$ & 12 & $10 / 62$ & 16 & 0.48 \\
\hline Positive SPTinhalant $£$ & $1 / 51$ & 2 & $4 / 62$ & 6 & 0.37 \\
\hline Any positive SPT $\S$ & $6 / 52$ & 12 & $12 / 62$ & 19 & 0.25 \\
\hline $\operatorname{IgE}$ food $t$ & $8 / 48$ & 17 & $8 / 56$ & 14 & 0.73 \\
\hline IgE inhalant & $2 / 48$ & 4 & $3 / 56$ & 5 & 1.00 \\
\hline Any IgE $\S$ & $8 / 48$ & 17 & $7 / 56$ & 13 & 0.55 \\
\hline IgE mediated food reaction $\mathbb{I}$ & $2 / 54$ & 4 & $9 / 65$ & 12 & 0.10 \\
\hline
\end{tabular}




\begin{tabular}{lcc|cc|c} 
IgE associated eczema** & $3 / 54$ & 6 & $6 / 63 \dagger \dagger$ & 10 & 0.50 \\
IgE associated asthmałt & $2 / 54$ & 4 & $4 / 64 \#$ & 6 & 0.69 \\
IgE mediated rhinoconjunctivits $\alpha$ & $1 / 54$ & 2 & $2 / 65$ & 3 & 0.68 \\
Any IgE associated disease & $4 / 54$ & 7 & $9 / 63$ & 14 & 0.24
\end{tabular}

$*=6,12$ and/ or 24 months, $\dagger=\chi^{2}$ - test, $+=$ egg, milk and/or wheat, $\S=$ egg, milk, wheat, cat, birch, timothy, $\|=12$ and / or 24 months, II =Food reaction and sensitisation to the particular food (egg or milk), $* *=$ Eczema and sensitisation, $\dagger \dagger=$ Two children with eczema and negative SPT's were excluded from the analysis due to missing $\operatorname{IgE}$ data, $++=$ Asthma and sensitisation, \# = one child with asthma and negative SPT's, was excluded from the analysis due to missing IgE data, $a=$ Rhinoconjunctivits and sensitisation, $£=$ cat, birch and/or timothy.

The total $\mathrm{n}$ values in each group vary due to missing IgE and SPT data caused by technical difficulties. 
Table 2. The risk (odds ratio $=$ OR) of developing positive skin prick tests against foods and symptoms of allergic disease in children of mothers supplemented with $\omega-3$ PUFA or placebo during pregnancy and lactation. All the data is presented as cumulative incidence for the first 24 months of life of the children. The OR were adjusted for effect modifiers identified in the multiple regression model.

Crude OR

Adjusted OR

\begin{tabular}{|c|c|c|c|c|c|c|}
\hline & OR & $95 \% \mathrm{CI}$ & $\mathrm{p}$-value & $\mathrm{aOR}$ & $95 \% \mathrm{CI}$ & $\mathrm{p}$-value \\
\hline Placebo group & 1.0 & & & & 1.0 & \\
\hline \multicolumn{7}{|l|}{$\omega-3$ supplementation } \\
\hline All SPT & 0.42 & $0.18-1.0$ & 0.05 & $0.43^{\mathrm{e}}$ & $0.17-1.1$ & 0.06 \\
\hline SPT egg & 0.37 & $0.14-0.98$ & 0.045 & $0.37^{\mathrm{e}}$ & $0.13-1.0$ & 0.05 \\
\hline SPT food ${ }^{\mathrm{a}}$ & 0.35 & $0.14-0.87$ & 0.02 & $0.34^{\mathrm{e}}$ & $0.13-0.88$ & 0.03 \\
\hline $\begin{array}{l}\text { IgE mediated food } \\
\text { reactions }{ }^{b} \\
\text { IgE associated }\end{array}$ & 0.21 & $0.06-0.79$ & 0.02 & $0.26^{\mathrm{f}}$ & $0.07-0.99$ & 0.049 \\
\hline $\begin{array}{l}\text { Eczema }^{\mathrm{c}} \\
\text { IgE associated }\end{array}$ & 0.33 & $0.11-0.97$ & 0.04 & $0.33^{\mathrm{g}}$ & $0.1-1.10$ & 0.06 \\
\hline Disease $^{\mathrm{d}}$ & 0.28 & $0.10-0.77$ & 0.01 & $0.29^{\mathrm{g}}$ & $0.1-0.86$ & 0.03 \\
\hline
\end{tabular}

$\mathrm{a}=$ positive SPT to egg, milk and/or wheat.

$\mathrm{b}=$ clinical food reaction and positive SPT/ IgE to the particular food.

$\mathrm{c}=$ clinical diagnosis of eczema and positive SPT/IgE to egg, milk and/or wheat.

$\mathrm{d}=$ eczema, food reaction, asthma and / or rhinoconjunctivitis AND sensitisation.

$\mathrm{e}=$ OR adjusted for AA (arachidonic acid) levels in maternal phospholipids at inclusion and breastfeeding fully until 6 months

$\mathrm{f}=$ OR adjusted for AA levels in maternal phospholipids at inclusion and allergic symptoms in mother.

$\mathrm{g}=\mathrm{OR}$ adjusted for AA levels in maternal phospholipids at inclusion, eczema in the family and caesarean section. 
Table 3. Proportions of LCPUFA in plasma phospholipids of mothers and children

Mother,

one week after delivery

\begin{tabular}{|c|c|c|c|c|c|c|c|c|c|c|c|c|c|c|c|}
\hline \multirow[b]{3}{*}{ C18:2n-6 (LA) } & \multicolumn{3}{|c|}{ one week after delivery } & \multicolumn{3}{|c|}{ Cord blood } & \multicolumn{3}{|c|}{ Infant, 3 months } & \multicolumn{3}{|c|}{ Infant, 12 months } & \multicolumn{3}{|c|}{ Child, 24 months } \\
\hline & $\begin{array}{c}\omega-3 \\
(\mathrm{n}=51) \\
\text { mean }(\mathrm{SD})\end{array}$ & $\begin{array}{c}\text { placebo } \\
(\mathrm{n}=62) \\
\text { mean }(\mathrm{SD})\end{array}$ & $\mathrm{p}$ II & $\begin{array}{c}\omega-3 \\
(\mathrm{n}=48) \\
\text { mean }(\mathrm{SD})\end{array}$ & $\begin{array}{c}\text { placebo } \\
(\mathrm{n}=56) \\
\text { mean }(\mathrm{SD})\end{array}$ & $\mathrm{p} \mathbb{1}$ & $\begin{array}{c}\omega-3 \\
(\mathrm{n}=34) \\
\text { mean }(\mathrm{SD})\end{array}$ & $\begin{array}{c}\text { placebo } \\
(\mathrm{n}=39) \\
\text { mean }(\mathrm{SD})\end{array}$ & $\mathrm{p} \mathbb{I}$ & $\begin{array}{c}\omega-3 \\
(\mathrm{n}=43) \\
\text { mean }(\mathrm{SD})\end{array}$ & $\begin{array}{c}\text { placebo } \\
(\mathrm{n}=44) \\
\text { mean }(\mathrm{SD})\end{array}$ & pII & $\begin{array}{c}\omega-3 \\
(\mathrm{n}=41) \\
\text { mean }(\mathrm{SD})\end{array}$ & $\begin{array}{c}\text { placebo } \\
(\mathrm{n}=42) \\
\text { mean }(\mathrm{SD})\end{array}$ & pdl \\
\hline & $15.2(2.3)$ & $20.1(3.0)$ & $<0.001$ & $6.0(1.1)$ & $6.3(1.0)$ & 0.14 & $16.4(3.3)$ & $18.7(2.3)$ & 0.001 & $22.2(2.1)$ & $22.5(2.4)$ & 0.45 & $20.0(2.3)$ & $20.5(1.9)$ & 0.31 \\
\hline C20:4n-6 (AA) & $8.1(1.6)$ & $10.2(2.0)$ & $<0.001$ & $12.6(1.6)$ & $16.0(1.4)$ & $<0.001$ & $8.6(1.4)$ & $10.6(1.9)$ & $<0.001$ & $8.1(1.1)$ & $8.2(1.3)$ & 0.61 & $9.1(1.3)$ & $8.8(1.1)$ & 0.20 \\
\hline C18: 3n-3 (LNA) & $0.4(0.1)$ & $0.4(0.1)$ & 0.21 & $0.2(0.05)$ & $0.1(0.02)$ & $<0.001$ & $0.2(0.04)$ & $0.2(0.03)$ & 0.14 & $0.3(0.06)$ & $0.3(0.08)$ & 0.32 & $0.28(0.06)$ & $0.28(0.07)$ & 0.96 \\
\hline C20:5n-3 (EPA) & $7.6(2.5)$ & $1.3(0.6)$ & $<0.001 \S$ & $2.7(0.9)$ & $0.5(0.2)$ & $<0.001 \S$ & $3.7(2.0)$ & $0.7(0.3)$ & $<0.001 \S$ & $0.8(0.5)$ & $0.6(0.3)$ & $0.03 \S$ & $0.82(0.5)$ & $0.83(0.5)$ & $0.95 \S$ \\
\hline C22:6n-3 (DHA) & $7.9(1.5)$ & $5.2(1.6)$ & $<0.001$ & $10.1(2.1)$ & $8.3(1.8)$ & $<0.001$ & $8.2(1.9)$ & $6.1(1.3)$ & $<0.001$ & $4.6(1.9)$ & $3.8(1.3)$ & 0.008 & $3.9(0.9)$ & $4.0(1.3)$ & 0.67 \\
\hline $\begin{array}{l}\text { C20:4n-6/C20:5n-3 } \\
\text { (AA/EPA) }\end{array}$ & $1.4(1.3)$ & $8.9(3.6)$ & 0.001 & $5.9(4.0)$ & $38.1(17.5)$ & 0.001 & 4. (6.4) & $17.9(0.5)$ & $<0.01$ & $13.0(6.0)$ & $16.3(6.9)$ & 0.02 & 12.9 (4.6) & $13.1(5.8)$ & 0.85 \\
\hline
\end{tabular}

$\mathbb{I}=$ Student's $t$-test

$\S=$ Mann-Whitney test showed similar results. 
Table 4. DHA (C22: 6n-3), and EPA (C20: 5n-3) proportions and AA (C18: 2n-6)/EPA (C20: 5n-3) ratios in maternal and infant plasma phospholipids related to number of allergic symptoms, with or without sensitisation, in the children up to two years of age. Information is given on all mothers/infants with available samples, regardless of maternal group allocation.

\begin{tabular}{|c|c|c|c|c|c|c|c|c|c|}
\hline & \multicolumn{2}{|c|}{ No allergic symptoms } & \multicolumn{2}{|c|}{ One allergic symptom* } & \multirow[b]{2}{*}{$\begin{array}{c}\text { p vs. no allergic } \\
\text { symptoms }\end{array}$} & \multicolumn{2}{|c|}{$>1$ allergic symptom* } & \multirow[b]{2}{*}{$\begin{array}{c}\text { p vs. no allergic } \\
\text { symptoms }\end{array}$} \\
\hline & & $\mathrm{n}$ & $\mathrm{mol} \%$ & $\mathrm{n}$ & $\mathrm{mol} \%$ & & $\mathrm{n}$ & $\mathrm{mol} \%$ & \\
\hline \multicolumn{2}{|c|}{ Mother EPA ${ }^{\#}$} & 67 & $2.5(1.4-8.2)$ & 25 & $1.8(1.0-8.6)$ & 0.62 & 21 & $1.5(0.8-5.2)$ & 0.02 \\
\hline & DHA $^{£}$ & 67 & $6.6(2.1)$ & 25 & $6.9(2.0)$ & 0.60 & 21 & $5.6(1.8)$ & 0.049 \\
\hline & $\mathrm{AA} / \mathrm{EPA}^{\#}$ & 67 & $4.1(1.0-7.9)$ & 25 & $6.2(0.8-8.6)$ & 0.99 & 21 & $7.7(1.2-11)$ & 0.03 \\
\hline \multirow[t]{3}{*}{ Infant } & $\mathrm{EPA} \mathrm{cb}^{\#}$ & 62 & $0.9(0.5-2.7)$ & 24 & $0.9(0.6-3.1)$ & 0.45 & 20 & $0.5(0.3-2.1)$ & 0.048 \\
\hline & DHA $\mathrm{cb}^{\mathfrak{f}}$ & 62 & $9.4(2.3)$ & 24 & $9.0(2.1)$ & 0.48 & 20 & $8.8(1.5)$ & 0.19 \\
\hline & $\mathrm{AA} / \mathrm{EPA} \mathrm{cb}^{\#}$ & 62 & $17(4.5-36)$ & 24 & $18(3.6-27)$ & 0.38 & 20 & $29(6.0-53)$ & 0.08 \\
\hline \multirow[t]{3}{*}{ Infant } & EPA $3 m^{\#}$ & 44 & $1.5(0.7-4.6)$ & 15 & $0.8(0.5-2.4)$ & 0.24 & 16 & $0.6(0.5-1.8)$ & 0.02 \\
\hline & DHA $3 m^{\mathfrak{f}}$ & 44 & $7.5(1.8)$ & 15 & $6.6(1.9)$ & 0.11 & 16 & $6.4(2.0)$ & 0.047 \\
\hline & AA/EPA $3 \mathrm{~m}^{\#}$ & 44 & $7.2(1.8-17)$ & 15 & $14(2.4-21)$ & 0.28 & 16 & $18(5.4-22)$ & 0.02 \\
\hline \multirow[t]{3}{*}{ Infant } & EPA $12 m^{\#}$ & 49 & $0.6(0.5-0.9)$ & 21 & $0.6(0.4-0.9)$ & 0.65 & 17 & $0.5(0.4-0.7)$ & 0.06 \\
\hline & DHA $12 \mathrm{~m}^{\mathfrak{f}}$ & 49 & $4.4(1.3)$ & 21 & $4.3(1.2)$ & 0.85 & 17 & $3.5(1.1)$ & 0.02 \\
\hline & AA/EPA $12 \mathrm{~m}^{\mathfrak{f}}$ & 49 & $14(6.3)$ & 21 & $13(9.0-20)$ & 0.73 & 17 & $16(12-20)$ & 0.14 \\
\hline \multirow[t]{3}{*}{ Infant } & EPA $24 m^{\#}$ & 49 & $0.7(0.6-0.9)$ & 18 & $0.7(0.6-0.8)$ & 0.47 & 16 & $0.5(0.5-0.9)$ & 0.09 \\
\hline & DHA $24 \mathrm{~m}^{\mathfrak{f}}$ & 49 & $4.2(1.2)$ & 18 & $4.0(0.9)$ & 0.36 & 16 & $3.4(1.1)$ & 0.02 \\
\hline & AA/EPA $24 \mathrm{~m}^{\mathfrak{f}}$ & 49 & $13(4.9)$ & 18 & $12(3.2)$ & 0.51 & 16 & $15.3(7.5)$ & 0.19 \\
\hline
\end{tabular}

* = eczema, food reaction, asthma or rhinoconjunctivitis. \# = not normally distributed ; median (first and third quartiles) are given, Mann -Witney test performed, $£=$ normally distributed ; mean (SD) are given, Student's $t$-test performed.

$\mathrm{cb}=$ cord blood. $\mathrm{m}=$ months 
